\title{
Pengembangan Alat Uji Efisiensi Lampu Berbasis Mikrokontroller Arduino Uno untuk Evaluasi Tingkat Pencahayaan Lampu Meja Belajar di Laboratorium Fisika-Mekatronika Politeknik STTT Bandung
}

\author{
Valentinus Galih Vidia Putra ${ }^{1}$, Andrian Wijayono ${ }^{2}$ Ngadiyono $^{3}$, Endah Purnomosari ${ }^{4}$ \\ 1,2,3,4Jurusan Teknik Tekstil, Politeknik STTT Bandung, Bandung \\ Jalan Jakarta No.31 Bandung, 40272, Indonesia \\ E-mail: valentinus@kemenperin.go.id
}

\begin{abstract}
Abstrak
Pada penelitian ini telah dirancang suatu alat uji efisiensi lampu menggunakan mikrokontroller Arduino UNO dalam upaya untuk memberikan pemahaman pemanfaatan penerapan hukum ohm pada praktikum fisika dasar. Prototipe alat uji efisiensi lampu ini menggunakan piranti sensor LDR dan sebuah resistor yang dikoneksikan ke piranti mikrokontroller arduino sebagai pendeteksi intensitas cahaya, sedangkan variasi daya listrik digunakan sebuah variac AC dengan jarak lampu ke sensor bernilai konstan. Hasil penelitian dengan metode eksperimen memperlihatkan bahwa besar efisiensi lampu dapat diperoleh melalui kurva gradient lumensitas terhadap daya listrik. Besar efisiensi lampu adalah sebesar 16.935 lumen/watt dan rerata resistansi didapatkan sebesar 983.01 $\Omega$ serta Besar lux rerata adalah E rerata $=337,05$ lux pada 157,68 Lumen dan Besar lux maksimal rerata adalah E rerata $=453,35$ lux dan besar lumensitas rerata adalah pada 208,54 Lumen.
\end{abstract}

Kata Kunci: Hambatan, Arus, Tegangan, Listrik, Arduino

\begin{abstract}
In this research, a light efficiency test tool has been designed using an Arduino UNO microcontroller to provide an understanding of the use of the ohm law application in basic physics practicum. This lamp efficiency test prototype uses an LDR sensor device and a resistor connected to the Arduino microcontroller as a light intensity detector, while the variation of electrical power is used by an AC variac with the lamp distance to the sensor having a constant value. The experimental results showed that the efficiency of the lamp can be obtained through a gradient of the luminosity curve on electric power. The efficiency of the lamp is $16.935 \mathrm{Im} /$ watt and the average resistance can be obtained on $983.01 \Omega$ which the intensity in lux is 337,05 lux on 157,68 Lm and the maximum intensity in lux can be obtained on 453,35 lux on 208,54 Lm.
\end{abstract}

Keywords: Resistance, Current, Voltage, Electricity, Arduino

\section{PENDAHULUAN}

Penerapan mikrokontroller sebagai alat penunjang pada kegiatan praktikum dan riset telah banyak digunakan pada beberapa bidang. Beberapa peneliti, seperti Badamasi (2014), Putra \& Purnomosari (2015), Raine (1945), Putra, Ngadiono, \& Purnomosari (2016), González et al. (2019), Dean \& Rane (2013),
Kondalkaret al. (2019), Hoffmann, Eilebrecht \& Leonhardt (2011) menggunakan piranti mikrokontroller untuk pengukuran suatu besaran-besaran fisika. Picker et al. (1971), Sreejith et al. (2015), Halliday, Resnick \& Walker (1997), Putra (2017) dan Putra, Ngadiono, \& Purnomosari (2019) menyatakan bahwa adanya daya listrik dalam piranti mikrokontroller akan menghasilkan suatu bentuk energi lain yaitu berupa panas ataupun 
cahaya yang diakibatkan pergerakan muatan pada rangkaian. Laju pergerakan muatan dan gesekan antar muatan akan mengakibatkan energi panas dan juga energi cahaya pada suatu bahan. Beberapa peneliti seperti Putra, Ngadiono, \& Purnomosari (2019), Sreejith et al. (2015) dan Salvo et al. (2010) menyatakan bahwa kajian mengenai cahaya dan panas yang ditimbulkan oleh arus listrik beserta sifat termodinamikanya adalah suatu topik penelitian yang menarik untuk dikaji.

Menurut Afinidad (2010), Atmodipuro (2000) dan Vincent et al. (1989) sistem pencahayaan pada suatu tempat dapat menunjang performansi kerja di tempat kerja, seperti di laboratorium yang merupakan salah satu tempat kerja yang mana sebagian besar kegiatannya sangat mengandalkan mata. Menurut Afinidad (2010), pencahayaan yang baik di laboratorium akan meningkatkan kenyamanan dalam bekerja bagi mahasiswa dan juga tenaga pengajar dalam melakukan eksperimen dan proses pembelajaran. Laboratorium Fisika- Mekatrionika Tekstil di lingkunganPoliteknik STTT Bandung merupakan sarana yang sangat penting bagi mahasiswa serta staf pengajar untuk melakukan proses pembelajaran dan eksperimen serta juga penelitian lanjut dalam bidang tekstil dan fisika terutama pada bidang elektronika tekstil, mekatronika tekstil dan rekayasa tekstil dan apparel. Pencahayaan yang baik pada suatu laboratorium umumnya akan meningkatkan kenyamanan dalam bekerja, sehingga suatu laboratorium yang baik memerlukan suatu pencahayaan dengan intensitas pencahayaan yang cukup untuk dapat mendukung aktivitas civitas akademika untuk terus aktif dalam berkarya. Menurut Afinidad (2010). Mata, yang merupakan salah satu alat penangkap cahaya, dapat menerjemahkan energi cahaya menjadi suatu impuls saraf, yang dapat ditransmisikan ke suatu korteks visual pada otak. Suatu cara perlindungan terhadap mata sebagai organ sensorik harus menjadi prioritas tinggi dalam setiap program keselamatan dan kesehatan kerja. Adanya kelelahan pada mata (salah satu organ sensorik pada panca indera) merupakan akibat adanya tegangan pada syaraf-syaraf mata yang merupakan organ sensorik penglihatan. Kelelahan pada organ sensorik mata disebabkan oleh tegangan apda syaraf dan juga stress yang tinggi pada single function pada mata. Stress yang persisten pada otot Ciliary Muscle dapat terjadi pada saat seseorang menyalakan inspeksi pada obyek-obyek yang berukuran kecil dan pada jarak dekat serta dalam waktu lama, dan stress pada retina dapat terjadi bila terdapat kontras yang berlebihan dalam penglihatan dan waktu pengamatan yang cukup lama. Dwiyanto \& Sukawi (2013). Stranks (2006) menyatakan bahwa pencahayaan adalah salah satu bagian terpenting dalam suatu lingkungan tempat kerja. Pentingnya pencahayaan pada lampu juga dijelaskan oleh Imansyah (2003) yang menyatakan bahwa kelelahan organ sensorik seperti mata dapat ditandai oleh beberapa faktor seperti: a) Iritasi pada mata; b) Double vision; c) Daya akomodasi dan konvergensi menurun; d) Sakit pada kepala; serta e) Ketajaman penglihatan yang menurun. Menurut beberapa peneliti Dwiyanto \& Sukawi (2013), Stranks (2006), Imansyah (2003) dan Stranks (2006), dalam desain pencahayaan diperlukan beberapa aspek seperti: a) Kuantitas cahaya yang diperlukan dalam satuan lux dan b) Kualitas pencahayaan (seperti kondisi silau, sorotan warna dan level terang). Beberapa peneliti Dwiyanto \& Sukawi (2013), Stranks (2006), Imansyah (2003) dan Stranks (2006) menjelaskan bahwa pekerjaan yang memerlukan suatu fokus mata yang detail dan baik seperti pada industri elektronik, laboratorium elektronika dan produksi tekstil memerlukan besar intensitas cahaya rerata dengan range minimal mulai dari 200 lux hingga range maksimal 500 lux. Dalam melakukan evaluasi tingkat pencahayaan di laboratorium Fisika-Mekatronika Tekstil Politeknik STTT Bandung, maka pada penelitian ini dirancang suatu prototipe alat uji efisiensi lampu dengan menggunakan piranti mikrokontroller Arduino Uno dengan besar jarak dari lampu ke sensor dipilih berdasarkan jarak rerata lampu belajar terhadap mahasiswa di laboratorium Fisika Politeknik STTT 
Bandung.

\section{METODE/EKSPERIMEN}

\section{Alat dan Bahan}

Pada metode eksperimen dijelaskan mengenai alat dan bahan, skema percobaan serta prosedur kerja. Berikut ini merupakan alat dan bahan yang digunakan:

1. AC amperemeter

2. AC voltmeter

3. Meja dudukan

4. Tahanan geser (Variac)

5. Lampu dengan daya 60 watt

6. Mikrokontroller Arduino Uno

7. Sensor LDR

8. Monitor

9. Kabel penghubung

10. Sumber arus

\section{Langkah Kerja}

Prosedur pengukuran besar efisiensi dan tingkat pencahayaan lampu dapat dijelaskan sebagai berikut (Gambar 1 dan Gambar 2):

1. Rangkaian disusun seperti pada Gambar 1 dan Gambar 2.

2. Sensor dan monitor diaktifkan dan lampu dinyalakan dengan melakukan variasi arus listrik

3. Besar variasi arus listrik dan hasil output tegangan serta intensitas cahaya dalam lux dicatat

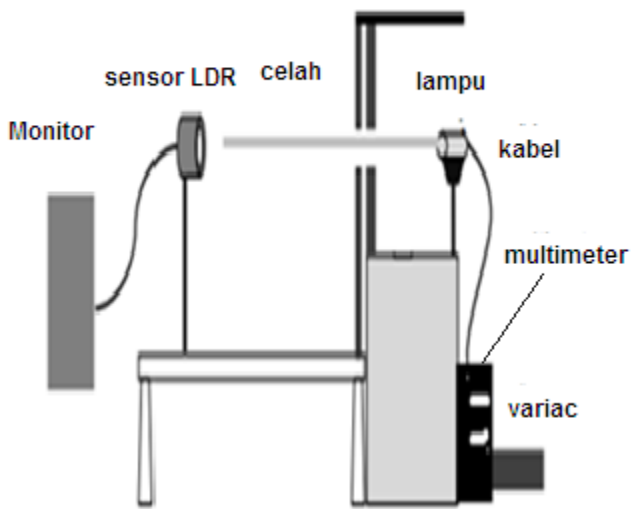

Gambar 1. Skema Percobaan

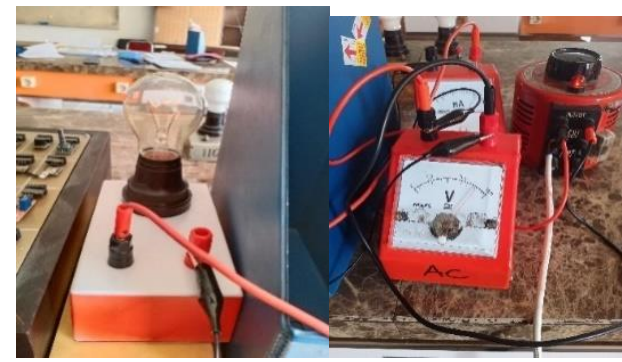

Gambar 2. Beberapa alat dan bahan dalam penelitian

\section{HASIL DAN PEMBAHASAN}

Berikut dijelaskan hasil penelitian dan pembahasan pada lampu pijar berdaya maksimal 60 watt untuk tegangan 220 volt AC. Berikut besar perhitungan resistansi untuk variasi besar tegangan dan arus pada Tabel 1.

Tabel 1. Perhitungan resistansi untuk variasi arus dan tegangan

\begin{tabular}{cccc}
\hline Percobaan & $\begin{array}{c}\text { Voltmeter } \\
(\mathrm{V} \pm 2,5) \mathrm{V}\end{array}$ & $\begin{array}{c}\text { KuatArus } \\
(\mathrm{I} \pm 0,01) \mathrm{A}\end{array}$ & $\mathrm{R}(\Omega)$ \\
\hline $\mathrm{Ke}-1$ & $40 \pm 2,5$ & $0,05 \pm 0,01$ & $\mathrm{R}=800 \Omega$ \\
$\mathrm{Ke}-2$ & $65 \pm 2,5$ & $0,09 \pm 0,01$ & $\mathrm{R}=722,2 \Omega$ \\
$\mathrm{Ke}-3$ & $90 \pm 2,5$ & $0,1 \pm 0,01$ & $\mathrm{R}=900 \Omega$ \\
$\mathrm{Ke}-4$ & $115 \pm 2,5$ & $0,11 \pm 0,01$ & $\mathrm{R}=1045,45 \Omega$ \\
$\mathrm{Ke}-5$ & $140 \pm 2,5$ & $0,12 \pm 0,01$ & $\mathrm{R}=1166,66 \Omega$ \\
\hline
\end{tabular}

Jarak Lampu ke LDR (r) dipilih berdasarkan jarak rerata lampu belajar terhadap mahasiswa di laboratorium Politeknik STTT Bandung yaitu sebesar 19,3 x 10-2 m dan dengan luasan area paparan lampu adalah sebesar $A=4 \pi r^{2}=4 \cdot 3,14 \cdot\left(19,3 \cdot 10^{-2}\right)^{2}=$ $0,47 \mathrm{~m}$. Pada percobaan ini digunakan jenis lampu Pijar 60 Watt dengan hambatan setiap lampu beserta ralatnya, pada setiap kuat arus dan beda potensial, di setiap percobaan dapat dirumuskan pada persamaan (1) hingga persamaan (15)

$$
\begin{gathered}
50 \mathrm{~mA}=\frac{50}{1000}=0,05 \mathrm{~A} \\
\mathrm{R}=\frac{V}{I}=\frac{40}{0,05}=800 \Omega \\
\Delta R=\left|\frac{1}{I} \Delta V\right|+\left|\frac{\mathrm{V}}{\mathrm{I}^{2}} \Delta \mathrm{I}\right| \\
=\left|\frac{1}{0,05} 2,5\right|+\left|\frac{40}{0,05^{2}} 0,01\right| \\
=210 \Omega
\end{gathered}
$$


68 | JIPFRI (Jurnal Inovasi Pendidikan Fisika dan Riset Ilmiah), Vol. 4 No. 2, November 2020

$R \pm \Delta R=(800 \pm 210) \Omega$

$90 \mathrm{~mA}=\frac{90}{1000}=0,09 \mathrm{~A}$

$$
\mathrm{R}=\frac{V}{I}=\frac{65}{0,09}=722,22 \Omega
$$

$$
\begin{gathered}
\Delta R=\left|\frac{1}{I} \Delta V\right|+\left|\frac{\mathrm{V}}{\mathrm{I}^{2}} \Delta \mathrm{I}\right| \\
=\left|\frac{1}{0,09} 2,5\right|+\left|\frac{65}{0,09^{2}} 0,01\right| \\
=108,02 \Omega
\end{gathered}
$$$$
R \pm \Delta R=(722,22 \Omega \pm 108,02) \Omega
$$

$$
\begin{aligned}
100 \mathrm{~mA} & =\frac{100}{1000}=0,1 \mathrm{~A} \\
\mathrm{R} & =\frac{V}{I}=\frac{90}{0,1}=900 \Omega \\
\Delta R & =\left|\frac{1}{I} \Delta V\right|+\left|\frac{\mathrm{V}}{\mathrm{I}^{2}} \Delta \mathrm{I}\right| \\
& =\left|\frac{1}{0,1} 2,5\right|+\left|\frac{90}{0,1^{2}} 0,01\right|
\end{aligned}
$$$$
=115 \Omega
$$$$
R \pm \Delta R=(900 \pm 115) \Omega
$$

$$
110 \mathrm{~mA}=\frac{110}{1000}=0,11 \mathrm{~A}
$$$$
\mathrm{R}=\frac{V}{I}=\frac{115}{0,11}=1045,45 \Omega
$$$$
\Delta R=\left|\frac{1}{I} \Delta V\right|+\left|\frac{\mathrm{V}}{\mathrm{I}^{2}} \Delta \mathrm{I}\right|
$$$$
=\left|\frac{1}{0,11} 2,5\right|+\left|\frac{115}{0,11^{2}} 0,01\right|
$$

$$
=117,76 \Omega
$$

$$
R \pm \Delta R=(1045,45 \pm 117,76) \Omega
$$

$$
\begin{aligned}
120 \mathrm{~mA} & =\frac{120}{1000}=0,12 \mathrm{~A} \\
\mathrm{R} & =\frac{V}{I}=\frac{140}{0,12}=1166,66 \Omega \\
\Delta R & =\left|\frac{1}{I} \Delta V\right|+\left|\frac{\mathrm{V}}{\mathrm{I}^{2}} \Delta \mathrm{I}\right| \\
& =\left|\frac{1}{0,12} 2,5\right|+\left|\frac{140}{0,12^{2}} 0,01\right|
\end{aligned}
$$

$$
=118,05 \Omega
$$

$$
R \pm \Delta R=(1166,66 \Omega \pm 118,05) \Omega
$$

Untuk menentukan besar rerata resistansi maka dapat ditentukan menggunakan kurva tegangan terhadap arus seperti pada Gambar 3 di bawah.

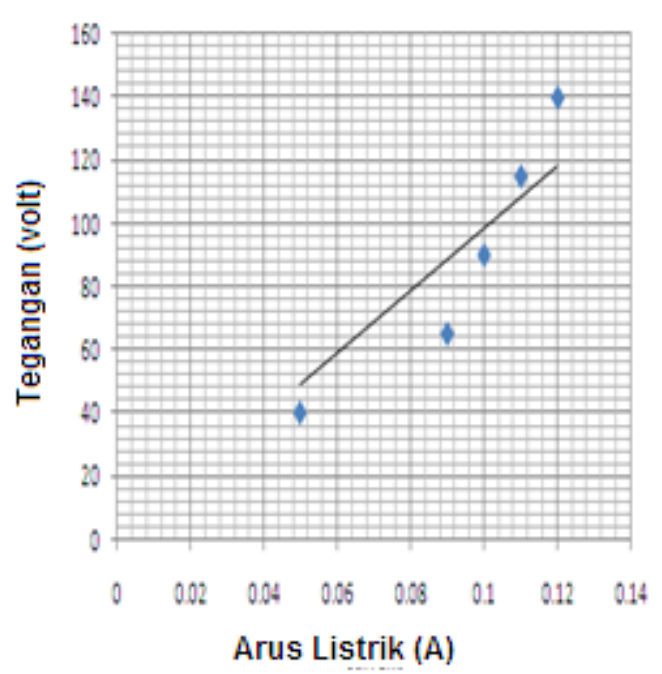

Gambar 3. Tegangan (volt) vs arus listrik (A) dengan $V=983.01 \mathrm{I}$

Besar rerata resistansi didapatkan sebesar $983.01 \Omega$. Daya lampu yang diberikan oleh lampu pada percobaan dapat diperlihatkan pada persamaan (16) untuk arus $50 \mathrm{~mA}=0,05$ A dan hambatan $R_{L}=800 \Omega$ seperti pada Persamaan (16) hingga persamaan (18).

$$
\begin{aligned}
& \mathrm{P}=\mathrm{I}^{2} \times \mathrm{R}_{\mathrm{L}}=0,05^{2} \times 800=2 \text { watt } \\
& \Delta P=2 I \times \Delta I+I^{2} \times \Delta R \\
& =2 \times 0,05 \times 0,01+0,05^{2} \times 210 \\
& =0,52 \mathrm{watt} \\
& P \pm \Delta P=(2,00 \pm 0,5) \text { watt }
\end{aligned}
$$

Besar daya listrik pada lampu dengan arus listrik sebesar $90 \mathrm{~mA}=0,09 \mathrm{~A}$ dengan $\mathrm{R} L=$ $722,22 \Omega$.

$$
\begin{aligned}
& P=I^{2} \times R L=0,09^{2} \times 722,22=5,84 \text { wat } \\
& \Delta P=2 I \times \Delta I+I^{2} \times \Delta R \\
& =2 \times 0,09 \times 0,01+0,09^{2} \times 108,02 \\
& =0,87 \text { watt } \\
& P \pm \Delta P=(5,84 \pm 0,87) w a t t
\end{aligned}
$$

Besar daya listrik pada lampu dengan arus listrik sebesar $100 \mathrm{~mA}=0,1$ Adengan $R_{L}=$ $900 \Omega$, seperti pada Persamaan (19) hingga persamaan (21) di bawah

$$
\begin{aligned}
& P=I^{2} \times \mathrm{R} L=0,1^{2} \times 900=9 \text { watt } \\
& \Delta P=2 I \times \Delta I+I^{2} \times \Delta R \\
& \quad=2 \times 0,1 \times 0,01+0,1^{2} \times 115 \\
& \quad=1,15 \text { watt } \\
& P \pm \Delta P=(9,00 \pm 1,15) \text { watt }
\end{aligned}
$$


Besar daya listrik untuk $110 \mathrm{~mA}=0,11 \mathrm{~A}$ dan $\mathrm{R} L=1045,45 \Omega$ seperti pada Persamaan (22) hingga persamaan (24) di bawah

$$
\begin{aligned}
& \mathrm{P}=\mathrm{I}^{2} \times \mathrm{R} \mathrm{L}=0,11^{2} \times 045,45 \\
& =12,64 \mathrm{watt} \\
& \Delta P=2 \mathrm{I} \times \Delta I+I^{2} \times \Delta R \\
& =2 \times 0,11 \times 0,01+0,11^{2} \times 117,76 \\
& =1,42 \mathrm{watt} \\
& \quad \mathrm{P} \pm \Delta \mathrm{P}=(12,64 \pm 1,42) \text { watt }
\end{aligned}
$$

Besar daya listrik untuk $120 \mathrm{~mA}=0,12 \mathrm{~A}$ dan $R \mathrm{~L}=1166,66 \Omega$ yaitu seperti pada Persamaan (25) hingga persamaan (27) di bawah sebesar $P=I^{2} \times R L=0,12^{2} \times 1166,66=16,79$ watt

$$
\begin{aligned}
& \Delta P=2 I \times \Delta I+I^{2} \times \Delta R \\
& =2 \times 0,12 \times 0,01+0,12^{2} \times 118,05 \\
& =1,7 \text { watt } \\
& P \pm \Delta P=(16,79 \pm 1,70) \text { watt }
\end{aligned}
$$

Besar rerata lumen lampu pada setiap percobaanyang didapatkan dari layar monitor mikrokontroller arduino dapat diperlihatkan pada Tabel 2 di bawah

Tabel 2. Besar intensitas cahaya dalam luxpada percobaan untuk daya lampu 2 watt

\begin{tabular}{lccc}
\hline \multicolumn{4}{c}{ Besar intensitas cahaya dalam lux } \\
\hline 352 & 266 & 355 & 354 \\
350 & 291 & 354 & 354 \\
311 & 346 & 354 & 354 \\
306 & 345 & 353 & 354 \\
288 & 347 & 353 & 354 \\
\hline
\end{tabular}

Besar lux rerata adalah $\mathrm{E}$ rerata = 337,05 lux dan besar lumensitas rerata adalah $\varnothing=E \times A=337,05 \times\left(4 \pi r^{2}\right)=337,05 \times 0,46=$ 157,68 Lumen (dapat diperlihatkan pada Tabel 3 di bawah)

Tabel 3. Besar intensitas cahaya dalam luxpada percobaan untuk daya5,84 watt

\begin{tabular}{lccr}
\hline \multicolumn{4}{c}{ Besar intensitas cahaya dalam lux } \\
\hline 316 & 466 & 395 & 452 \\
404 & 414 & 498 & 456 \\
443 & 488 & 386 & 412 \\
438 & 402 & 490 & 491 \\
438 & 495 & 391 & 385 \\
\hline
\end{tabular}

Besar lux rerata adalah $\mathrm{E}$ rerata $=433$ lux dan besar lumensitas rerata adalah $\emptyset=\mathrm{E} x$ $A=433 \times\left(4 \pi r^{2}\right)=433 \times 0,46=197,13$ Lumen (dapat diperlihatkan pada Tabel 4 di bawah)
Tabel 4. Besar intensitas cahaya dalam luxpada percobaan untuk daya9 watt

\begin{tabular}{llll}
\multicolumn{4}{c}{ Besar intensitas cahaya dalam lux } \\
\hline 482 & 405 & 370 & 385 \\
470 & 453 & 395 & 461 \\
433 & 487 & 459 & 475 \\
367 & 473 & 481 & 369 \\
380 & 420 & 406 & 400 \\
\hline
\end{tabular}

Besar lux rerata adalah $E$ rerata $=428,55$ lux dan besar lumensitas rerata adalah $\emptyset=E x$ $A=428,55 \times\left(4 \pi r^{2}\right)=428,55 \times 0,46=199,18$ Lumen (dapat diperlihatkan pada Tabel 5 di bawah)

Tabel 5. Besar intensitas cahaya dalam luxpada percobaan untuk daya12,64 watt

\begin{tabular}{lccc}
\hline \multicolumn{4}{c}{ Besar intensitas cahaya dalam lux } \\
\hline 481 & 392 & 389 & 395 \\
483 & 432 & 463 & 400 \\
487 & 476 & 482 & 461 \\
473 & 485 & 486 & 473 \\
428 & 459 & 441 & 481 \\
\hline
\end{tabular}

Besar lux rerata adalah $E$ rerata $=453,35$ luxdan besar lumensitas rerata adalah $\emptyset=\mathrm{E} x$ $A=453,35 \times\left(4 \pi r^{2}\right)=453,35 \times 0,46=208,54$ Lumen (dapat diperlihatkan pada Tabel 6 di bawah)

Tabel 6. Besar intensitas cahaya dalam luxpada percobaan untuk daya16,79 watt

\begin{tabular}{lccr}
\hline \multicolumn{4}{c}{ Besar intensitas cahaya dalam lux } \\
\hline 454 & 470 & 480 & 482 \\
409 & 473 & 481 & 483 \\
382 & 477 & 481 & 485 \\
435 & 479 & 481 & 483 \\
462 & 480 & 482 & 468 \\
\hline
\end{tabular}

Besar lux rerata adalah $E$ rerata $=466,35$ luxdan besar lumensitas rerata adalah $\emptyset=\mathrm{Ex}$ $\mathrm{A}=466,35 \times\left(4 \pi r^{2}\right) \quad=466,35 \times 0,46=$ 214,52 Lumen. Untuk menentukan besar efisiensi rerata maka dapat ditentukan menggunakan kurva lumensitas terhadap daya listrik seperti pada Gambar 4. 


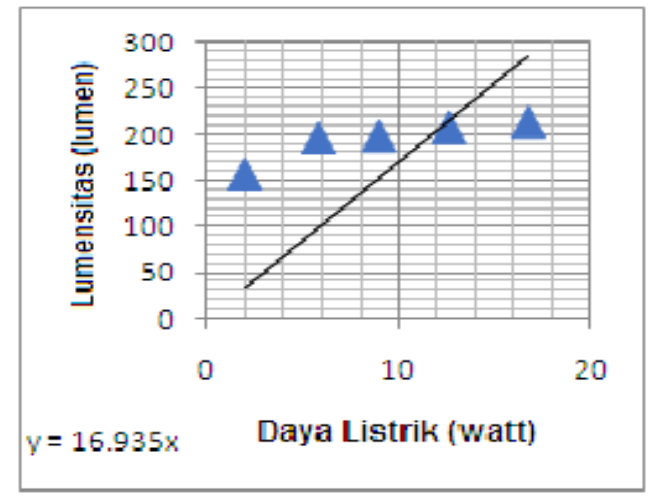

Gambar 4. Lumensity (lumen) vs daya listrik (watt) dengan besar efisiensi sebesar 16.935 lumen/watt

\section{PENUTUP}

Pada penelitian ini telah dirancang suatu alat uji efisiensi lampu menggunakan mikrokontroller arduino uno dalam upaya untuk memberikan pemahaman pemanfaatan penerapan hukum ohm pada praktikum fisika dasar. Hasil penelitian memperlihatkan bahwa besar efisiensi lampu dapat diperoleh melalui kurva gradient lumensitas terhadap daya listrik. Besar efisiensi lampu adalah sebesar 16.935 lumen/watt dan rerata resistansi didapatkan sebesar $983.01 \Omega$ serta Besar lux rerata adalah E rerata $=337,05$ lux pada 157,68 Lumen dan Besar lux maksimal rerata adalah $\mathrm{E}$ rerata $=$ 453,35 luxdan besar lumensitas rerata adalah pada 208,54 Lumen.

\section{UCAPAN TERIMAKASIH}

Ucapan terima kasih ditujukan kepada Lab. Fisika-Mekatronika Politeknik STTT Bandung, serta rekan-rekan dosen Politeknik STTT Bandung yang telah memberikan dukungan pada penelitian ini.

\section{REFERENSI}

Afinidad, T. C. B. (2010). Workstation and workspace ergonomics in philippine libraries: an emerging priority. Journal of Philippine Librarianship, 30(1), 2144.
Atmodipuro, T. R. (2000). Sistem pencahayaan sebagai penunjang performansi kerja. In Proceeding Seminar Nasional Ergonomi.

Vincent, A. J., Spierings, E. L., \& Messinger, H. B. (1989). A controlled study of visual symptoms and eye strain factors in chronic headache. Headache: The Journal of Head and Face Pain, 29(8), 523-527.

https://doi.org/10.1111/j.1526-

4610.1989.hed2908523.x

Badamasi, Y. A. (2014, September). The working principle of an Arduino. In 2014 11th international conference on electronics, computer and computation (ICECCO) (pp. 1-4). IEEE. https://doi.org/10.1109/ICECCO.2014. 6997578

Dean, R. N., \& Rane, A. K. (2013). A digital frequency-locked loop system for capacitance measurement. IEEE Transactions on Instrumentation and Measurement, 62(4), 777-784. https://doi.org/10.1109/TIM.2013.2240 092

Dwiyanto, A., \& Sukawi, (2013). Kajian Optimasi

Pencahayaan Alami pada Ruang Perkuliahan Jurusan Arsitektur Fakultas Teknik Universitas Diponegoro. Journal of Architecture, 2.

González, T., J. D., Torres-Sánchez, R., BlayaRos, P. J., Toledo-Moreo, A. B., Jiménez-Buendía, M., \& Soto-Valles, F. (2019). Design and calibration of a low-cost SDI-12 soil moisture sensor. Sensors, 19(3), 491. https://doi.org/10.3390/s19030491

Halliday, D., Resnick, R. and Walker, J. (1997). Fundamenthal of Physics-Extended, 5thJohn Wiley \& Sons, New York.

Hoffmann, T., Eilebrecht, B., \& Leonhardt, S. 
(2010). Respiratory monitoring system on the basis of capacitive textile force sensors. IEEE sensors journal, 11(5), 1112-1119.

https://doi.org/10.1109/JSEN.2010.20 82524

Imansyah, B. (2003, Februari). Dampak Sistem Pencahayaan Bagi Kesehatan Mata. http://www.sinarharapan.co.id/berita/ 0611/28/ipt02.html. Diakses pada tanggal 12 Februari 2016

Kondalkar, V. V., Ryu, G., Lee, Y., \& Lee, K. (2019). Development of highly sensitive and stable humidity sensor for real-time monitoring of dissolved moisture in transformer-insulating oil. Sensors and Actuators B: Chemical, 286, 377-385. https://doi.org/10.1016/j.snb.2019.01.1 62

Putra, V. G. V., \& Purnomosari, E. (2015). Pengantar Eksperimen Fisika. Yogyakarta: CV. Mulia Jaya. ISBN: 978.602.72713.0.2.

Putra, V. G. V., Ngadiono., \& Purnomosari, E. (2016). Pengantar Listrik Magnet dan Terapannya. Yogyakarta: CV. Mulia Jaya. ISBN: 978-602- 72713-2-6 1.

Putra, V. G. V. (2017). Pengantar Fisika Dasar. CV.Mulia Jaya Publisher, Yogyakarta.

Putra, V. G. V., Ngadiono., \& Purnomosari, E. (2019). Pengantar Praktikum Mekatronika Tekstil. Yogyakarta: CV. Mulia Jaya. ISBN: 9786025165832.

Picker, P., Leduc, P. A., Philip, P. R., \& Desnoyers, J. E. (1971). Heat capacity of solutions by flow microcalorimetry. The Journal of Chemical Thermodynamics, 3(5), 631642. https://doi.org/10.1016/S00219614(71)80 084-8

Raine, H. C., Richards, R. B., \& Ryder, H. (1945). The heat capacity, heat of solution, and crystallinity of polythene. Transactions of the Faraday Society, 41 , 56-64. https://doi.org/10.1039/TF9454100056

Salvo, P., Di Francesco, F., Costanzo, D., Ferrari, C., Trivella, M. G., \& De Rossi, D. (2010). A wearable sensor for measuring sweat rate. IEEE Sensors Journal, 10(10) 1557-1558. https://doi.org/10.1109/JSEN.2010.20 46634

Sreejith, K. R., Shyamkumar, P. G., Appu, R. P., \& Sreedevi, C. (2015, December). A low cost automated specific heat capacity meter for liquids. In 2015 International Conference on Trends in Automation, Communications and Computing Technology (I-TACT15) $($ pp. 1-4). IEEE. https://doi.org/10.1109/ITACT.2015.74 92691

Stranks, J. (2006). The manager's guide to health and safety at work. Kogan Page Publishers. 